\title{
Molina Cano, Jerónimo. Raymond Aron, realista político. Del maquiavelismo a la critica de las religiones seculares. Madrid: Sequitur, 2013, 86 páginas.
}

\author{
Fabricio Ezequiel Castro \\ Universidad de Buenos Aires/Instituto de Investigaciones Gino Germani/CONICET, Argentina \\ fabricioecastro@hotmail.com
}

Raymond Aron, intelectual francés que vivió entre 1905 y 1983, presenció los principales fenómenos políticos del siglo XX: las guerras mundiales, los totalitarismos, la guerra fría, con la única excepción de la caída del muro de Berlín y la disolución del régimen soviético, hecho notable que da fin a tan agitado siglo. Menos estudiado en la actualidad, puede considerárselo como una referencia inexcusable del pensamiento político en tiempos de lo que él mismo llamó la "sociedad industrial", forma de organización característica de su época. Jerónimo Molina Cano, profesor de la Universidad de Murcia y autor de trabajos previos sobre Julian Freund y Carl Schmitt, se involucra en la obra de Raymond Aron para defender la tesis acerca de la presencia de un punto de vista realista en el francés.

Más allá de la innegable intención del texto de focalizar en la figura de Aron, lo cierto es que el libro se eleva sobre ese objetivo para elaborar un ensayo sobre el realismo político, visión que postula (y aquí nuevamente se cuela Carl Schmitt) la "seriedad de la vida" a la vez que intenta diferenciarse de lo que Molina Cano denomina "politiqueo", entendido como aquel devenir algo banal de la política cotidiana. El realismo político no excluye necesariamente este aspecto, pero lo supera para defender la persistencia de marcos de pensamiento permanentes aplicables a la política, aunque inferiores al grado de veracidad de las ciencias formales. Este rasgo se presenta sin lugar a dudas en este escrito del profesor Molina Cano, por lo que su texto puede evaluarse a nivel general como un libro realista sobre el realismo político y, a nivel particular, como un esfuerzo de identificación de la presencia de este concepto en la obra de Raymond Aron. Doble provecho se obtiene del texto, entonces.

La política, advierte nuestro autor, involucra en última instancia una reflexión antropológica, un decir sobre el hombre. La perspectiva realista no es la excepción. Asimilada generalmente a una antropología pesimista, propia de autores como Maquiavelo y Morgenthau, lo cierto es que dicha tesis no es homologable enseguida a una visión de este tipo. En efecto, el realismo debería reconocer e incorporar la presencia de actitudes altruistas, desinteresadas y colectivas, además del autointerés y del egoísmo con el que describe típicamente al hombre, pues este es siempre ambas cosas. Es el abundante conjunto de actitudes que puede desplegar. Por eso, aclara Molina Cano (2013): "la política abarca además los sentimientos nobles y el amor a la patria" (p. 8).

El realismo, y esto el autor lo resalta con insistencia a lo largo de su texto, es también un punto de vista metodológico, una posición/predisposición para la investigación que no es otra cosa que la "imaginación del desastre” o, en palabras de Julian Freund, el “ponerse en lo peor”. El buen método realista, el político capaz de observar la realidad con esta habilidad ("don", lo llama Molina Cano), ve la mejor instancia de la prudencia en este acercamiento desconfiado al análisis de los hechos políticos. Por su parte, el científico resume este don en la postulación metodológica de la superioridad de la observación por sobre la ética. El hallazgo de esta vocación en la obra de Raymond Aron es precisamente el objetivo de Molina Cano. 
Un problema disparado por las observaciones del profesor español reside en que la "imaginación del desastre" restringe las bases antropológicas que reclama la premisa del hombre que "es" por sobre el que "debe ser". La fantasía de la peor posibilidad ("El desastre") se recuesta, provisoriamente al menos, en la pesadilla del peor hombre posible. Esa reducción metodológica es tal vez inevitable, pero no deja de ser llamativa cuando previamente se advirtió acerca de la necesidad de llevar hasta sus últimas consecuencias la antropología realista para incluir al altruismo. Así, el realismo de la imaginación negativa esconde una paradójica contracara reduccionista, en lo inmediato de su propio reclamo.

No obstante el comentario precedente, el realismo, como postura política y metodológica, obtiene de la obra de Aron un buen ejemplo de su desarrollo y permite, subsidiariamente, reposicionar un nuevo punto de vista en el autor francés.

El gran fenómeno político que atraviesa la vida de Raymond Aron es el totalitarismo. De allí vendrán sus reflexiones más interesantes y sorprendentes (cuando diga, por ejemplo, que las democracias occidentales deberán aprender de algunas de las virtudes de los regímenes totalitarios) y que revelarán la vocación realista de sus análisis. Si en un principio verá a los regímenes totalitarios bajo la óptica del "maquiavelismo", abandonará esta posición más tarde en pos de otro de los temas más importantes del libro, cuyo tratamiento Molina Cano no agota en Aron: las religiones seculares, insertándose así en otro campo importante de la reflexión sobre la política.

***

En nuestra reconstrucción, no respetaremos a rajatabla la división de capítulos establecida por Molina Cano, quien titula temáticamente las características que observa en la obra de Aron (Primado de lo político Ideología - Maquiavelismo - Realismo Político - Religiones seculares) debido a que, a nuestro modo de leer, los temas atraviesan a todos los capítulos. Lo interesante del trabajo que presentamos aquí es precisamente la habilidad de su autor para conectar los temas que prefiere estudiar sin estancarse en compartimentos, pues tiene claro que un pensador trabaja con redes conceptuales y no con separaciones de conceptos.

$* * *$

En Raymond Aron, la aplicación del método realista evidencia la prioridad de la observación por sobre la ética. Resultado de ello, el pensador francés asumirá todas las consecuencias de su postulado en ideas tales como la autonomía de la política, el carácter indeseable de las elecciones políticas (que recuerda al famoso "pacto con el diablo" señalado por Max Weber, sobre lo inevitable de decidir lo imperfecto en la política) y, la tercera consecuencia señalada por Molina Cano, la superioridad de la política como hecho social englobante de las demás esferas de la vida. Dicha perspectiva de análisis la aplica Aron a varios objetos y sujetos de reflexión, pero muy especialmente al totalitarismo. A los regímenes totalitarios los considera una variante de la sociedad industrial y los coloca junto a las democracias, ambos especies de ese mismo género, sin implicar por ello la búsqueda de una teoría general de la política. Tal vez, esto explique el oficio periodístico del autor, consecuencia probable del carácter provisorio de todo conocimiento político, que puede impulsar a la escritura de coyuntura, dado el bajo grado de formalización científica del método realista.

Estas elecciones teóricas posicionan a Aron dentro del espectro de pensamiento de su época. Como anticomunista constante fue un crítico enfático de la moralina del intelectual francés de los años sesenta, que inclina a la izquierda hacia el denuncismo cómodo que prescinde de las complicaciones de la decisión y del poder. Pero también se distancia del incipiente neoliberalismo que en los años 60 comienza a abrirse paso hacia su predominio actual y cuya tesis economicista recuerda paradójicamente al marxismo, pues la idea de que la planificación conduce de modo indudable al autoritarismo, amén de falsa, es determinista como premisa científica. ${ }^{1}$ Al contrario de estos puntos de vista, el intelectual francés se declara ideológicamente keynesiano. Por último, se diferencia del liberalismo ortodoxo que plantea la neutralidad valorativa del Estado, al proclamar la necesidad de una comunidad anclada en valores indiscutibles, aún en las plurales y tolerantes democracias occidentales, un tema cuya importancia política no puede ser negada por el temor a los regímenes de partido único. 
Este rechazo por igual al marxismo y al neoliberalismo surge precisamente de la imposibilidad de subsumir la política a la economía. La política es una esfera de acción autónoma, dice Aron, en coincidencia con la larga trayectoria del realismo político. Pero no se trata únicamente de la independencia de la esfera de la política, sino también de su primacía. En términos conceptuales, aquí afirma Aron lo que suele distinguirse como "La" política y "Lo" político, esto último como aquello que abarca de modo superior al resto de las actividades humanas. En palabras de Molina Cano (2013): "cuando Aron se refiere al primado de lo político [afirma que] en un sentido antropológico, la política es más importante que la economía porque afecta, 'por definición', al sentido de la existencia" (p. 25).

Decíamos que Aron fue un autor atravesado por los problemas típicos del siglo XX. Precisamente su contexto habilita la creación de un concepto sociohistórico esencial: la sociedad industrial. Sin embargo, esta idea no debe hacer pensar en una explicación materialista, de tipo estructural clasista, sino más bien en la descripción de un proceso de decisión política. La politización de este concepto sociológico le permite incorporar a los regímenes totalitarios y a los democrático-liberales occidentales bajo una misma categoría, porque el siglo XX no habría proporcionado más que dos decisiones posibles de organización política de la sociedad: las del Estado laico de partidos y las del Estado ideológico o de partido único.

Decisiones fueron las que generaron resultados políticos para conformar eso que se llama sociedad industrial. Lo dicho, comprendemos a partir del trabajo de Molina Cano, no reviste importancia sólo por la recolocación taxonómica entre regímenes democráticos y totalitarios, sino sobre todo porque antecede a la afirmación de Aron acerca de la convergencia futura entre los dos sistemas en el mundo internacional. Dicha predicción fue equivocada, pero aún así da a ver la idea aroniana sobre la relación entre estos regímenes, que descontextualizada puede parecer más que polémica: hay que rescatar y apropiarse de las mejores políticas implementadas por los totalitarismos. Si ambas son sociedades industriales, debería ser posible aprender de las totalitarias, una vez depurados todos sus evidentes crímenes e inconvenientes. Por lo tanto, recomponer los elementos del régimen totalitario podrá, aunque parezca insólito, mejorar a nuestras sociedades demoliberales.

Tres campos de estudio se extraen de la observación de Aron sobre los regímenes totalitarios reconstruidos por Molina Cano. Las ideologías, el maquiavelismo y las religiones seculares denotan distintos puntos de vista que a lo largo de su obra Raymond Aron utilizó para iluminar su comprensión sobre los totalitarismos, pero también para determinar qué elementos podemos reutilizar en favor de las democracias occidentales.

En el primer aspecto, la sociedad industrial se caracteriza por la producción de una burocracia intelectual que opera como una especie de poder cultural. Esto es patente en el régimen soviético, razón por la cual Aron lo llama "sinistrismo".

El maquiavelismo, o la cuestión de los medios de la política, aparece en Raymond Aron asociado a una disputa con Jacques Maritain. Este último resalta el carácter destructivo del maquiavelismo, de la fuerza como potencia desinteresada que desprecia la pregunta por el bien común. Aron asume la posición contraria, en él la fuerza-potencia de los medios no imposibilita el bien común. Más bien lo contrario, opera como su complemento, pues la potencia-fuerza del medio también explica la realización efectiva del bien común. En su versión totalitaria, Aron lo descubre como una forma moderna de tiranía, formula extrema del "maquiavelismo".

Probablemente, la cuestión relativa a la religión civil sea otro de los temas generales más importantes del texto que presentamos, aunque por debajo del realismo político. Molina Cano incorpora a Aron dentro de la tradición de autores que reflexionaron sobre esta cuestión (desde Rousseau y Condorcet, hasta Le Bon y Pareto). Lograr un efecto similar al de las religiones tradicionales en los regímenes políticos secularizados caracteriza a las reflexiones sobre este tópico. Es en el siglo XIX, destaca Molina Cano, donde comienza a sospecharse de la forma religiosa del socialismo. Sin embargo, la importancia social de aquello que en la tradición de pensamiento político se denomina religión política traspasa al totalitarismo para convertirse también en una de las necesidades de los regímenes demo-liberales. 
Con todo, el análisis de la sociedad industrial en su aspecto totalitario y desde una metodología realista permitieron extraer tres componentes de la política, el maquiavelismo, las religiones seculares y la ideología, que Aron reclama también para las sociedades democráticas, previa disminución de su intensidad. Así, propone un uso moderado de las ideologías, aboga por un cierto tipo de fe secular proporcionada e inspirada en las formas religiosas como instrumento necesario para la construcción de comunidad y, finalmente, un maquiavelismo moderado dentro del cual el autor podría ser posicionado, aunque él prefiera definirse como un "observador comprometido". La moderación respecto de estos tres puntos, surgidos de una reflexión sobre el totalitarismo, ingresan en los regímenes occidentales precisamente por constituir también sociedades industriales, es decir por compartir un género común con aquel.

Como pudo verse, el trabajo del profesor Molina Cano extrajo una serie de reflexiones políticas sobre la obra de Aron, que a partir de su hipotética conversión al realismo ilumina aspectos usualmente pasados por alto, dado que muchos autores rápidamente deciden tomarlo por liberal.

A nuestro modo de ver, Molina Cano habilita con su trabajo una línea de investigación sobre la relación entre la obra de Raymond Aron y el pensamiento conservador que radicalizaría aún más su corrimiento de las filas del liberalismo. El profesor español, sin profundizar sobre el tema, lo sugiere en varios pasajes. Naturalmente, el realismo tiene muchas vinculaciones con el conservadorismo (la baja predisposición a la fantasía política, el anclaje a la realidad para el estudio de lo político) pero también distancias identificadas en cierta predisposición a concebir una relación estrecha entre moral y política, presente en los conservadores desde Edmund Burke (Nisbet, 1986). Basten dos ejemplos extraídos de la obra que reseñamos. En el primero el intelectual francés afirma: "las democracias son esencialmente conservadoras, pues aspiran a conservar los valores tradicionales sobre los que se funda nuestra civilización” (Molina Cano, 2013, p. 51). El segundo, traído por el mismo Molina Cano (2013), acerca de la afiliación de cierto espíritu moderado inglés al momento de observar la política: "Aron prefiere la experiencia inglesa de la política, 'apegada siempre a la realidad'” (p. 18).

Por último, el texto deja pendiente el problema de la distinción ética entre el totalitarismo y la democracia, difícil de abarcar para el método realista, y sin la cual no podría responderse filosóficamente el por qué de la preferencia por las democracias.

\section{ReFERENCIAS}

Hayek, F. (1978). Camino de servidumbre. Madrid: Alianza.

Molina Cano, J. (2013). Raymond Aron, realista politico. Del maquiavelismo a la critica de las religiones seculares. Madrid: Sequitur.

Nisbet, R. (1986). Conservadurismo. Madrid: Alianza.

\section{Notas}

1 A nuestro modo de ver, la simplificación neoliberal es incluso peor: para Hayek (1978), no solo la planificación conduce al totalitarismo, sino que el mero acto de intervención y regulación estatal en la economía es en sí mismo autoritario. 